\title{
Opportunistic Disclosure in the Inter-Organizational Relationships
}

by

\section{Grete Oll}

Discussion Papers on Business and Economics

No. $21 / 2014$

FURTHER INFORMATION Department of Business and Economics Faculty of Business and Social Sciences University of Southern Denmark Campusvej 55 DK-5230 Odense M Denmark 


\title{
Opportunistic Disclosure in the Inter-Organizational Relationships
}

\author{
Grete Oll *
}

December 4, 2014

\begin{abstract}
The purpose of this paper is to explore the effect the accounting system choice has, when the supplier discloses accounting information opportunistically in an Inter-Organizational Relationship. A contract governs the trade and specifies: (i) a cost reimbursement and (ii) a profit sharing arrangement.

The supplier's opportunism emerges as he can manages the rate that is used for allocating overhead costs to the reimbursed product. Two methods of allocation rate management are available, leading to two distinct inefficiencies. First, the supplier can use some input factors in excess (Real Cost Management). Second, the supplier can influence the trade quantity (Real Activity Management).

We find that even with opportunistic disclosure, the total profit of the relationship exceeds the profit under the arm's-length relationship. With a traditional accounting system, the supplier engages in Real Cost Management if the total overhead cost is high compared to the total direct labour cost. With an Activity-Based Accounting system, the supplier engages in Real Cost Management when the overhead cost of the traded product is small compared to the overhead cost of other products.

We further show that the supplier engage in Real Activity Management regardless of the accounting system. However, the size and the direction of the quantity distortion depends on the accounting system.
\end{abstract}

Key words: management accounting and control; inter-organizational relationships; cost reimbursement; profit-sharing; accounting system choice; private disclosure.

JEL Classification: M41

${ }^{*}$ Department of Business and Economics, University of Southern Denmark, Campusvej 55, 5320 Odense M, Denmark. E-mail: oll@sam.sdu.dk 


\section{Introduction}

The extent of voluntary disclosure of proprietary and strategic information is significantly higher within close buyer-supplier relationships compared to arm's-length relationships. Cost and production process information is exchanged in order to identify and implement efficiency improving investments, and forecasts are shared and combined with cost information to increase production planning efficiency (Baiman and Rajan, 2002b).

Most of the theoretical research on voluntary disclosure can be related to the arm's-length relationships, as after the disclosure the disclosing party cannot control who accesses the information. This strand of voluntary disclosure literature emphasizes the self-interest in all disclosure decisions. ${ }^{1}$

Little is known about opportunistic disclosure within close buyer-supplier relationships. Few case studies of buyer-supplier relationships mention fear of opportunistic behaviour, and then mostly as a reason of failure (Dekker, 2008; Kajüter and Kulmala, 2005; Seal et al., 1999). Two papers focus more on the role of opportunism in voluntary disclosure decisions. Baiman and Rajan (2002b) model a buyer-supplier relationships, in which opportunistic behaviour hinders disclosure of an investment opportunity. Drake and Haka (2008) conduct an experiment to study interaction between the opportunistic behaviour and characteristics of information disclosed. They find that less fine cost information is disclosed, when the trading partner can behave opportunistically. The paper in hand also explores the interaction between opportunistic behaviour and the structure of accounting cost information. Contrary to the papers mentioned above, this paper focuses on the opportunistic behaviour of the partner who discloses the information, i.e. opportunistic disclosure.

The present paper explores the supplier's incentives to act opportunistically when accounting information is shared with the buyer. The sharing of cost information is necessary as the supplier has better knowledge about his own production technology. At the same time, the cost of production affects the buyer's strategic decision (quantity).

This paper demonstrates that even opportunistic information disclosure can improve efficiency compared to the arm's-length trade. One reason for this is that the disclosure opportunism is limited by the use of accounting reports and an incentive contract. However, it is also demonstrated that first-best cannot be obtained as even a limited opportunistic disclosure induces (i) quantity and (ii) input-factor distortion. The model constructs accounting reports based on both the traditional (volume-based) and the ABC (activity-based costing) methods. It is demonstrated that the interaction between opportunistic disclosure and accounting structure is conditional on

\footnotetext{
${ }^{1}$ Even when there are no frictions regarding distribution and communication of the information, it is the opportunistic behaviour of agents that results in unravelling. With frictions, the information disclosed is not complete (e.g., Dye, 1985; Verrecchia, 1983).
} 
the supplier's production technology. The model ignores relationship-specific investment, but has implications for the supplier's incentives to undertake these investments.

In the next section a short overview of the related literature is provided. In Section 3 the model is introduces and formal analysis is carried out in Section 4. Section 5 provides theoretical benchmarks necessary to interpret the numerical examples, which are presented in Section 6. Section 7 discusses the findings and suggest further research.

\section{$2 \quad$ Related Literature}

Baiman and Rajan (2002b) and Drake and Haka (2008) are the only two papers focusing directly on the effect of opportunistic disclosure in buyersupplier relationships. However, the focus in these two papers is on the opportunistic exploitation of the information disclosed.

Opportunistic behaviour (but not information disclosure) in buyer-supplier relationships has received attention in incomplete contracting literature (e.g., Aghion et al., 1994; Baiman et al., 2000; Bhattacharyya and Lafontaine, 1995; Che and Hausch, 1999; Demski and Sappington, 1991; Edlin and Hermalin, 2000; Grossman and Hart, 1986; MacLeod and Malcomson, 1993; Nöldeke and Schmidt, 1995; Smirnov and Wait, 2004; and an overview is provided in Baiman and Rajan, 2002a). The focus in this strand of research is on the effect the ex post renegotiation of the ex ante contract has on the ex ante investment incentives. An underlying assumption is that the ex ante contract will be renegotiated if at least one of the opportunistically behaving partners finds this to be in their interest. Consequently, the ex ante contract can at best structure the ex post negotiation. Further, the assumption is that ex post information between the buyer and the supplier is symmetric. In other words, it is assumed that a mechanism for non-opportunistic disclosure exists. This allows implementation of the generalized Nash bargaining concept as the solution to ex post bargaining problem. However, it is unclear why such a strong assumption about non-opportunistic disclosure exists in a framework that otherwise focuses on the consequences of opportunism. It is not clear what the implications of this assumption are on the investment inefficiency.

The accounting report is the disclosure mechanism implemented in this paper. Supplier's discretion in input-factor choice and the need for allocation of the cost of common factors create a possibility for opportunistic disclosure. However, this opportunism is limited as all accounting systems must follow some generally acceptable allocation method. Rogerson (1992) and Christensen and Demski (2003) investigate this phenomenon. Rogerson (1992) investigates the effect of cost reimbursement schemes in defence contracts, when the opportunistic disclosure of cost information affects the firm's rev- 
enues. The revenue effect is modelled through an arbitrary function, and accounting method implemented play no role. On the other hand, the focus of Christensen and Demski (2003) is solely on the interaction between the accounting method implemented and the mechanism enabling the cost report opportunism. There is no revenue effect and thus no countervailing incentives. The model in this paper combines the ideas of these two papers.

A number of case studies investigating the buyer-supplier relationships emphasize voluntary disclosure of cost and production technology information as the prerequisite of inter-organizational cost management (e.g., Agndal and Nilsson, 2008, 2009, 2010; Carr and Ng, 1995; Cooper and Slagmulder, 1999, 2004; Dekker, 2003; Kajüter and Kulmala, 2005; Munday, 1992; Seal et al., 1999). However, these case studies and field research does not include a detailed description of the disclosure mechanisms. In addition, discussions of opportunism in buyer-supplier relationships are seldom in this research strand. Exceptions are Dekker (2008), that employs transaction cost economics in the hypothesis development phase. He finds that opportunistic behaviour affects both the partner selection and the governance mechanism of the buyer-supplier relationship. Kajüter and Kulmala (2005) and Bastl et al. (2010) point to the fear of opportunistic behaviour as a factor inhibiting voluntary disclosure. Kajüter and Kulmala (2005, p. 184) argue that further research on the factors affecting voluntary disclosure in the buyer-supplier relationships is needed, as these factors determine the success or failure of the relationship.

\section{The Model}

Trade between a buyer and a supplier is modelled. The buyer operates at one end-user market, where the exogenously given inverse demand function is $p_{0}=a_{0}-b_{0} q$. $p_{0}$ denotes the unit price paid by the end-users and $q$ is the quantity sold. All $q$ units must be acquired from one supplier. Single sourcing of important components characterizes many inter-organizational relationships (henceforward IOR). Both the buyer and the supplier know the inverse demand function. This assumption focuses all attention on the supplier's opportunistic disclosure incentives. The buyer has no additional processing costs. ${ }^{2}$

The buyer has the formal authority ${ }^{3}$ to make the quantity decision. However, the information about the production process and the cost structure is the supplier's private knowledge, thus the cost of producing the product traded is the supplier's private knowledge as well. To make the quantity

\footnotetext{
${ }^{2}$ This is a simplifying assumption as any constant marginal cost can be normalized to zero by adjusting the inverse demand function.

${ }^{3}$ In the presence of information asymmetry, formal and real authority may not be allocated to same agents, e.g. Aghion and Tirole (1997).
} 
decision, the buyer therefore needs to receive a message about the trading price from the supplier.

When a trade between the buyer and the seller takes place under arm'slength conditions, then the message send by the supplier consist of only one variable, the wholesale price $w .^{4}$ Because of the double-marginalization, ${ }^{5}$ the arm's-length relationship is subject to efficiency loss.

Next subsection describes a contract that can mitigate the efficiency loss from double-marginalization. In the subsection 3.2 the supplier's production technology is introduced and the cost function is derived. Subsection 3.3 provides detail on the potential accounting systems. The last subsection provides the timeline.

\subsection{The Inter-Organizational Relationship Contract}

To mitigate the adverse effect of double-marginalization, the contract between the buyer and the supplier (henceforward IOR-contract) must govern two incentive issues. First, the reason for the efficiency loss is, that the per unit trading price is above the marginal cost. A cost based reimbursement can be the means for mitigating the gap between trading price and cost. The use of a two-part tariff could ensure that the supplier accepts the IOR-contract. ${ }^{6}$ However, a fixed payment combined with cost reimbursement does not align the supplier's incentives with the IOR's interest. The reason is, that the accounting cost report is limited to employing generally acceptable accounting methods for allocating cost of common factors.

The need to allocate common costs leaves room for managerial discretion in reporting product cost, even when the accounting system reports without errors. Rogerson (1992) and Christensen and Demski (2003) demonstrate that the managerial discretion lead to inefficient input-factor choices in order to allocate a larger share of the common cost to the reimbursed product. In other words, a cost reimbursement contract incentivises the manager to distort the cost allocation rate. This can be achieved either by manipulating the accounting system itself or by manipulating the variables that affect the allocation rate directly. The latter is possible only if the manager who makes the input-factor choices (and ultimately constructs the accounting report) have better information about the production process and consequently the cost structure, than the agent who reimburses the cost as reported by

\footnotetext{
${ }^{4}$ The wholesale price does not depend on the quantity, because the supplier knows the demand function, i.e. the buyer's response function.

${ }^{5}$ Double-marginalization arises when the supplier's wholesale price exceeds marginal cost and therefore induces the buyer to choose lower than optimal trade quantity. This is described in section 5.2, Benchmark II.

${ }^{6}$ The suppliers profit is zero, if the cost reimbursement is the only control implemented. under the outside option (i.e. the arm's-length relationship) the supplier's profit is above zero. A side payment to the supplier, compensating for the loss is sufficient to induce acceptance of the IOR-contract.
} 
the accounting system. This is the second incentive issue the IOR-contract must deal with. A profit sharing arrangement is proposed as the mechanism reducing this misalignment.

Definition 3.1. Real Cost Management (RCM) is the supplier's inefficient input-factor choice, where the sole purpose of the excessive use is to alter the accounting cost report.

\subsubsection{Supplier's Incentive Alignment}

Rogerson (1992) is the first to show that cost reimbursement contracts induce Real Cost Management (henceforward RCM). In Rogerson's model, the buyer can choose between multiple suppliers. Therefore RCM is limited such that the supplier's reported costs are marginally below the cost at which the buyer switches to another supplier. However, in close buyer-supplier relationships switching costs may be significantly higher than in defence contracts (the focus of Rogerson, 1992). Switching costs increase when one or both of the parties make relationship specific investments. Further, this early research does not endogenize the effect different accounting systems have on the RCM incentives. The interaction between accounting methods and RCM incentives is the main concern in Christensen and Demski (2003). In their paper, the switching cost is implicitly assumed to be infinite, i.e. the buyer must acquire the product from the specific supplier. Therefore the supplier engages in the maximum RCM, where the maximum is determined by some exogenous limit on input factors. The reason for maximum RCM in Christensen and Demski (2003) is that the supplier internalizes little to none of the real cost from the excessive input-factor choice. ${ }^{7}$

The research in hand also assumes infinitely high switching costs. Contrary to the previous research, the trade quantity is not fixed ${ }^{8}$ as the IOR as a unified entity faces a downwards sloping demand at the end-user market. The mechanism that limits RCM in Rogerson (1992) implies that a revenueor profit-sharing arrangement has the potential to limit RCM with variable trade quantity. The revenue- or profit-sharing contracts are argued to increase the alignment of the supplier's interests with the interests of the IOR (Cachon, 2003; Bhattacharyya and Lafontaine, 1995; Anderson and Dekker, 2009).

Let $\Pi$ denote the total IOR profit from the trade as reported by the buyer's accounting system ${ }^{9}$ and $\hat{C}(\cdot)$ the total cost of producing the traded units as reported by the supplier's accounting system.

\footnotetext{
${ }^{7}$ Except when $\mathrm{ABC}$ is implemented and the production technology exhibits constant returns to scale.

${ }^{8}$ In Rogerson (1992) if the transfer takes place, the trade quantity is fixed. In Christensen and Demski (2003) trade always takes place and one unit is exchanged.

${ }^{9}$ The implicit assumption is that the buyer's accounting system reports revenues without errors.
} 


$$
\Pi \equiv p_{0}(q) * q-\hat{C}(\cdot)
$$

The buyer keeps a fraction $\alpha$ of the IOR profit and the supplier receives the residual, i.e. $(1-\alpha) \Pi$.

If only the profit-sharing arrangement is implemented (i.e. $\alpha<1$ ) the supplier still needs to set a wholesale price. The wholesale price will be lower than without profit-sharing arrangement, but not equal to the marginal cost. The reasons is that the supplier internalizes the efficiency loss from doublemarginalization, but only partially.

\subsubsection{Supply Schedule and Cost Reimbursement}

The supplier commits to mitigating the efficiency loss from double-marginalization by accepting the cost reimbursement arrangement. However, the accounting report, upon which the reimbursement is based, is not timely for quantity decision.

Let $p_{t}(\cdot)$ denote the per unit trading price, when the relationship is governed by IOR-contract. The message to the buyer takes a form of a supply schedule $p_{t}(q)$. The buyer chooses a pair $\left(\tilde{q}, p_{t}(\tilde{q})\right)$, that maximizes her profit.

There are no restrictions on the functional form of the supply schedule. For example the supply schedule may 'jump' (i.e. is not smooth) when capacity constraints exist. However, the 'jump' in the supply schedule may exist because it is in the supplier's best interest to distort the buyer's formal quantity choice, not because a capacity limit is reached. Because the buyer does not know the supplier's production technology, it is impossible for the buyer to determine how closely the supply schedule reflects the underlying production technology. ${ }^{10}$ Similar arguments apply to a 'drop' in the supply schedule. Consequently the real authority to make the quantity decision is held by the supplier.

Let $\hat{q}$ denote the quantity that maximizes the supplier's profit.

Definition 3.2. Real Activity Management (RAM) is the trade quantity distortion that materializes because the supplier's profit maximizing

\footnotetext{
${ }^{10}$ Even when the buyer is aware about the supplier's ability to use the supply schedule to distort her formal quantity decision, the buyer cannot unravel the direction and magnitude because she does not have information about the supplier's production technology. Results in section 4.2.1 demonstrates that the supplier's incentive to distort trade quantity is affected by two factors, both of which depend on the supplier's production technology. First, whether the allocation rate is responsive to the changes in trade quantity. Second, how the cost of common factors changes with trade quantity. Most importantly, it is not sufficient that the buyer learns about the technical specifications of the product traded in the IOR. To unravel the supplier's incentives, the buyer must know the technical specification of all the other products produced by the supplier.
} 
quantity $(\hat{q})$ differs from the first-best trade quantity ${ }^{11}$ and the supplier uses the supply schedule to induce the buyer's best response $(\tilde{q})$ to be the same inefficient quantity.

The supplier's information advantages in constructing the supply schedule implies that $\hat{q}=\tilde{q}$. Therefore, in the following the trade quantity is simply denote $q$ unless it is necessary to express the buyer's and/or the supplier's quantity choice explicitly.

Numerical example in Section 6 illustrates the use and construction of the supply schedule.

\subsection{Supplier's Production Technology and Cost Function}

\section{Supplier's Production Technology}

The supplier manages a multi-product production facility, where some input factors are common. ${ }^{12}$ The first product is transferred to the buyer, the second product represents an aggregation of all other products, sold at a competitive market. For simplicity, production of the second product is fixed at the quantity $Q$ and it is sold at fixed revenue $R(Q)$. All products are produced using similar production technologies. The production technology uses direct labour and internally produced intermediary output (e.g., an activity) as inputs. Substitution between these two types of input is not possible. Denote as $x \in \mathbb{R}_{+}^{4}$ the vector of input factors the supplier acquires from exogenous markets (e.g., raw materials). The companion price vector is $P \in \mathbb{R}_{++}^{4}$.

$x_{1}$ is the total amount of direct labour used to produce $q$ units of the product traded between the buyer and the supplier. $x_{2}$ units of direct labour is used to produce $Q$ units of the other product. Both products have unique minimum requirement of direct labour $L_{i}(i=1,2)$. Therefore, sufficient amount of direct labour must be acquired from the factor-input market. This is formalized by following two constraints:

$$
\begin{aligned}
& x_{1} \geq L_{1} q \\
& x_{2} \geq L_{2} Q
\end{aligned}
$$

Let $y_{i}$ denote the amount of intermediary output. All units of $y_{1}$ are exclusively used to produce the product traded between the buyer and the supplier. Equivalently all units of $y_{2}$ are exclusively used for product two.

Input factors $x_{3}$ and $x_{4}$ are combined to produce the intermediary outputs $y_{1}$ and $y_{2}$. The production uses Cobb-Douglas production technology:

\footnotetext{
${ }^{11}$ The buyer's quantity decision is not distorted by the profit-sharing arrangement, i.e. when the buyer can acquire products at the marginal cost it is in her best interest to choose the first-best quantity.

${ }^{12}$ The cost allocation exercise is trivial if the supplier produces only one product.
} 


$$
\left(x_{3} x_{4}\right)^{\beta}=y_{1}+y_{2}
$$

where $\beta \in[0.5,1)$. The separable structure of the output from the CobbDouglas production process is assumed to induce objective cost allocation. ${ }^{13}$ Let $A_{i}$ denotes product $i$ 's minimum requirement of the intermediary output, such that:

$$
\begin{aligned}
& y_{1} \geq A_{1} q \\
& y_{2} \geq A_{2} Q
\end{aligned}
$$

Combining equations 3 and 4 (a,b), the formalized constraint on the production of intermediary inputs is:

$$
\left(x_{3} x_{4}\right)^{\beta} \geq A_{1} q+A_{2} Q=\bar{A}
$$

Let $\Omega=\left\{L_{1}, L_{2}, A_{1}, A_{2}, \beta\right\}$ represent supplier's production technology, i.e. all the variables that are the supplier's private knowledge. ${ }^{14}$

\section{Supplier's Cost function}

In this section the cost function for any possible $L_{i}, A_{i}, q, Q$ and $\beta$ is derived.

The supplier's cost function is determined by the following program:

$$
\min _{\mathbf{x}} C(q, Q ; P) \equiv \sum_{i=1}^{4} x_{i} P_{i}
$$

Subject to:

$$
\begin{array}{r}
x_{1} \geq L_{1} q \\
x_{2} \geq L_{2} Q \\
\left(x_{3} x_{4}\right)^{\beta} \geq \bar{A}
\end{array}
$$

The supplier's cost function is: ${ }^{15}$

$$
C(q, Q ; \mathbf{P})=P_{1} L_{1} q+P_{2} L_{2} Q+\bar{P}\left[A_{1} q+A_{2} Q\right]^{\frac{1}{2 \beta}}
$$

where $\bar{P} \equiv 2 \sqrt{P_{3} P_{4}}$ is the price of one unit of the intermediary output. The last term in (6) represents the total cost of common factors used in the production process.

\footnotetext{
${ }^{13}$ There is no need for managerial discretion in estimating the allocation rate (parameters) when the output from the intermediary production process is separable and used exclusively for one product.

${ }^{14}$ In addition $Q$ may be a private knowledge, but this is not an essential assumption for the further analysis.

${ }^{15}$ The derivation of the supplier's cost function can be found the appendix.
} 


\subsection{Supplier's Accounting System}

The supplier's accounting system is endogenized in this model, because he manages a multi-product firm, where common factors are used to produce the intermediary output. The cost information can be contracted upon only if the accounting system has registered and allocated the cost of common factors.

An accounting system deals with the cost of common factors by employing one of the generally acceptable allocation methods. In the broad perspective, two methods exist. First, the traditional accounting system uses the production volume or the cost of direct inputs to allocate the cost of common factors. The second allocation method allocates the cost of common factors based on the products' (estimated) use of the intermediary output. This type of accounting system is called Activity-Based Costing (ABC).

Which of the two accounting systems the supplier has implemented affects the precise nature of the opportunism in cost information disclosure (Christensen and Demski, 2003). Therefore, both the traditional (represented by the direct labour base, i.e. DL) and the activity-based costing systems are employed in the analysis below. Let $\eta$ denote the accounting system in place i.e. $\eta \in\{D L, A B C\}$. The cost report of an accounting system $\eta$ is denoted $\hat{C}_{\eta}(q, Q, m ; \mathbf{P})$. The variable $m$ is used to operationalize $\mathrm{RCM}$ in Sections 4 and 6.

This paper is only concerned with the opportunistic disclosure and not accounting manipulation or fraud. Therefore it is assumed that, conditional on the supplier's input-factor choices, the accounting system registers direct and total common factor costs as well as the use of intermediary output without errors.

\subsection{Timeline}

The timing of events is illustrated in Figure 1. The supplier is 'born' with a production technology and an accounting system are in place, i.e. at $t=-1, \Omega$ and $\eta$ are in place. At $t=0$ an opportunity to enter an IOR emerges. The buyer and the supplier agree on IOR-contract that specifies an open-book accounting arrangement to (i) mitigate the adverse effects of double-marginalization, i.e. the cost reimbursement and (ii) a profit-sharing arrangement to align incentives. At $t=1$ the supplier provides the supply schedule, from which the buyer chooses a price-quantity pair $\left(\tilde{q}, p_{t}(\tilde{q})\right)$ that maximizes her profit. At $t=2$ the supplier makes his input-factor choices and produces $q$ units. At $t=3$ products are transferred to the buyer, these are sold at the external end-user market, profits are realized and monetary payments according to the contract are made.

Supplier's revenue from the exogenous market is ignored in Sections 4 'The Analytical Approach' and 5 'Benchmarks'. This revenue has no effect 


\begin{tabular}{|c|c|c|c|c|}
\hline-1 & 0 & 1 & 2 & 3 \\
\hline $\begin{array}{l}\Omega, \eta \\
\text { in place }\end{array}$ & IOR contract & $\begin{array}{l}\text { Supply schedule: } \\
p_{t}(q) ; \\
\text { Buyer chooses } \\
\left(\tilde{q}, p_{t}(\tilde{q})\right)\end{array}$ & $\begin{array}{l}\text { Supplier's } \\
\text { input-factor } \\
\text { choice and } \\
\text { production }\end{array}$ & $\begin{array}{l}\text { Exchange of goods, } \\
\text { accounting report, } \\
\text { monetary payment }\end{array}$ \\
\hline
\end{tabular}

Figure 1: Timing of events

on the supplier's choices in IOR as both the selling price and quantity $(Q)$ are fixed.

\section{The Analytical Approach}

\subsection{Supplier's Programs with the IOR-Contract}

The supplier chooses simultaneously the per unit RCM and trade quantity $(q)$ to maximize his profit. The supplier has the real authority to make the quantity decision because he can use the supply schedule to affect the buyer's formal choice. ${ }^{16}$

As the cost function is already derived and substitution between direct and indirect input is not possible, RCM can be treated as additive. In the model, per unit RCM is denoted $m$. This allows us to construct an unconstrained program, ${ }^{17}$ which illuminates the source and magnitude of RCM (compared to a constrained program, where the factor inputs are the decision variables as well).

The supplier faces the following optimization problem:

$$
\begin{array}{r}
\max _{q, m} \pi^{S} \equiv(1-\alpha)\left(p_{0} q-\hat{C}_{\eta}(q, Q, m ; \mathbf{P})\right)- \\
{\left[C_{\eta}(q, Q, m ; \mathbf{P})-\hat{C}_{\eta}(q, Q, m ; \mathbf{p})\right]}
\end{array}
$$

subject to $m \geq 0, q \geq 0$.

The first term in equation (7) represents the supplier's share of the IOR profit. The profit is constructed by subtracting the product cost as reported by the supplier's accounting system from the revenues obtained at the enduser market (as in equation 1). The second part in equation (7) explicitly shows how supplier's cost structure is changed by the cost reimbursement

\footnotetext{
${ }^{16}$ The buyer cannot respond to the supplier's opportunistic use of the supply schedule, because she does not have necessary production technology information to determine the direction and magnitude of the distortion.

${ }^{17}$ Technically the program is still constrained as neither RCM or the trade quantity need to be non-negative. But as these are technical and not incentive related constraint, I call the program subject to these two constraints, an unconstrained program.
} 
agreement. The supplier fully internalizes only the residual costs, as reported by the accounting system $\left[C_{\eta}(\cdot)-\hat{C}_{\eta}(\cdot)\right]$. The reimbursed costs are internalized partially, the fraction $(1-\alpha)$ is carried by the supplier. Lastly, in addition to the exogenous parameters $\mathbf{P}$ and $\mathbf{Q}$, both the total costs and the accounting cost report depend on the quantity choice and RCM directly. In addition, the supplier's accounting system in place affects the cost report directly and RCM, RAM and thus the total cost of production.

\subsection{1 $\eta=D L$ : Direct Labour Based Accounting System}

When the supplier has implemented the traditional accounting system, then the RCM is implemented in the model by replacing $L_{1}$ in the cost function with $\left(L_{1}+m\right)$. By the assumption, substitution between the direct and indirect input factors is not possible. Therefore, when the supplier has implemented the direct labour based accounting system he cannot gain from excessive use of indirect input factors. The reason is that the allocation rate is determined solely by the use of the direct input. The purpose of RCM is to affect the allocation rate, thus there are no incentives to undertake inefficient actions that does not change the allocation rate. Employing similar Leontief production technology model, Christensen and Demski (2003, Proposition 2 and the following discussion) also argue for the efficiency in indirect input-factor choices with the direct labour based accounting system in place.

The supplier's total cost is:

$$
\begin{array}{r}
C_{D L}(q, Q, m ; \mathbf{P})=P_{1}\left(L_{1}+m\right) q+P_{2} L_{2} Q+\bar{P} \bar{A}(\mathbf{q})^{\frac{1}{2 \beta}}= \\
c_{d l}^{*}+P_{1} q m+c_{o h}^{*}
\end{array}
$$

where $c_{d l}^{*} \equiv P_{1} L_{1} q+P_{2} L_{2} Q$ stands for the total cost of direct labour input to produce both products, when there is no RCM. $P_{1} q m$ is the cost of RCM. Further, $c_{o h}^{*} \equiv \bar{P} \bar{A}(q, Q)^{\frac{1}{2 \beta}}$ denotes the cost of efficient indirect input.

Let $r_{D L}$ denote the direct labour based allocation rate used to allocate the cost of common factor to the reimbursed product.

$$
r_{D L} \equiv \frac{P_{1}\left(L_{1}+m\right) q}{c_{d l}^{*}+P_{1} q m}
$$

Then the cost report $\hat{C}_{D L}(q, Q, m ; \mathbf{P})$ is:

$$
\hat{C}_{D L}(q, Q, m ; \mathbf{P})=P_{1}\left(L_{1}+m\right) q+r_{D L} c_{o h}^{*}
$$

With the supplier's cost function and the cost report specified above the supplier's program with direct labour based accounting system is: 


$$
\begin{array}{r}
\max _{m, q} \pi_{D L}^{S} \equiv(1-\alpha)\left(a_{0}-b_{0} q\right) q-P_{2} L_{2} Q- \\
(1-\alpha) P_{1}\left(L_{1}+m\right) q-\left(1-\alpha r_{D L}\right) c_{o h}^{*}
\end{array}
$$

subject to $q, m \geq 0$.

The first term in the equation (10) is the supplier's share of the revenues generated by the trade. With the profit-sharing arrangement, the actual cost reimbursement is $\alpha \hat{C}(\cdot)$. The fraction of the costs reimbursed equals the buyer's share of the IOR profit. Further, $(1-\alpha) P_{1}\left(L_{1}+m\right) q$ represents the efficient direct labour cost and the cost of engaging in RCM, as carried by the supplier. The last term represents the fraction of indirect costs carried by the supplier. Changes in the cost of common factor is allocated to the traded product using $r_{D L}$, and of the allocated cost only the fraction $\alpha$ is reimbursed.

Equation (10) illustrates the tension in the supplier's incentives. With high $\alpha$, the supplier internalizes little of the real cost the excessive inputfactor choice entails. This incentivizes the supplier to engage in RCM and RAM. Further, when the supplier's share of the profit is low, he internalizes little of the revenue loss from RAM. ${ }^{18}$

\subsection{2 $\eta=A B C$ : Activity-Based Accounting System}

When the supplier has implemented the ABC system, then RCM is implemented in the model by replacing $A_{1}$ with $\left(A_{1}+m\right)$ in the cost function. In the $\mathrm{ABC}$ system, the supplier has no incentives to use direct labour input excessively. The reason is that the direct labour does not affect the allocation rate, i.e. there are no benefits. On the other hand, the excessive usage of the direct labour does impose a real cost to the supplier. He internalizes $(1-\alpha)$ of all costs related to the reimbursed product. Let $r_{A B C}$ be the allocation rate in the $\mathrm{ABC}$ system.

$$
r_{A B C}=\frac{\left(A_{1}+m\right) q}{\left(A_{1}+m\right) q+A_{2} Q}
$$

The supplier's cost function and the cost report are, respectively:

$$
\begin{array}{r}
C_{A B C}(q, Q, m ; \mathbf{P})=c_{d l}^{*}+\bar{P}\left[\left(A_{1}+m\right) q+A_{2} Q\right]^{\frac{1}{2 \beta}} \\
\hat{C}_{A B C}(q, Q, m ; \mathbf{P})=P_{1} L_{1} q+r_{A B C} \bar{P}\left[\left(A_{1}+m\right) q+A_{2} Q\right]^{\frac{1}{2 \beta}}
\end{array}
$$

\footnotetext{
${ }^{18} \mathrm{~A}$ revenue-sharing contract is one where the $\alpha$ in front of the last two terms in (10) is replaced with 1 . In that case, both the efficient and RCM cost of direct labour are eliminated from the supplier's objective function. With no effect on revenue (e.g., $q$ is fixed), it would always be in the supplier's interest to increase $r_{D L}$, i.e. engage in maximum RCM as in Christensen and Demski (2003).
} 
The supplier's program is:

$$
\begin{aligned}
\max _{q, m} \pi_{A B C}^{S} & \equiv(1-\alpha)(a-b q) q-c_{d l}^{*}-\bar{P}{\overline{A_{m}}}^{\frac{1}{2 \beta}} \\
& +\alpha\left(P_{1} L_{1} q+r_{A B C} \bar{P} \overline{A_{m}}{ }^{\frac{1}{2 \beta}}\right)
\end{aligned}
$$

where $\overline{A_{m}} \equiv\left[\left(A_{1}+m\right) q+A_{2} Q\right]$

In the direct labour-based accounting system, the efficient input choice and RCM interact only in determining the overhead cost allocation rate. With increasing returns to scale and the $\mathrm{ABC}$ system, the interaction of efficient input choice and RCM is more complex. Consequently, only direct labour costs can be identified at the efficient level.

\subsection{Non-Optimal Choices by the Supplier}

The supplier can engage the real cost management (RCM) and real activity management (RAM) simultaneously. RAM and RCM are studied separately, because the interaction between these two methods of allocation rate management is complex. That RCM and RAM are studied separately results in a more intuitive understanding of the mechanisms driving the supplier's incentives. In Section 4.2.1 it is assumed that $m=0$ and in Section 4.2.2 $q$ is held constant.

\subsubsection{Real Activity Management}

Proposition 1. With zero input per unit RCM and $\alpha>0$

i. Regardless of the accounting system in place the supplier engages in RAM, i.e. $\tilde{q}=\hat{q} \neq q^{*}$ if:

$$
\left(1-\alpha r_{\eta}\right) \frac{\partial c_{o h}^{*}}{\partial q} \neq \frac{\partial r_{\eta}}{\partial q} c_{o h}^{*}
$$

ii. The choice of accounting system is irrelevant for the magnitude (and direction) of RAM, i.e. $\hat{q}_{D L}=\hat{q}_{A B C}$ only if:

$$
\left(r_{A B C}-r_{D L}\right) \frac{\partial c_{o h}^{*}}{\partial q}=\left(\frac{\partial r_{D L}}{\partial q}-\frac{\partial r_{A B C}}{\partial q}\right) c_{o h}^{*}
$$

The proof follows from comparing the first-order conditions of equations (19), (10) and (12). ${ }^{19}$

\footnotetext{
${ }^{19}$ The proof can be found in the appendix.
} 
The supplier does not internalize the marginal revenue and the marginal cost fully. This is a necessary, but not sufficient, condition for an inefficient trade quantity to be implemented. The supplier engages in RAM because of the difference in the rate at which he internalizes marginal revenues and marginal cost, and this is solely caused by allocation of the cost of common factors. This is easily seen by ignoring overhead cost completely; then the supplier's first order condition $(1-\alpha)(a-2 b q)=(1-\alpha) P_{1} L_{1}$ has the same solution as first-best (without overhead).

The marginal indirect cost, internalized by the supplier, differs from the economic marginal cost, he should internalize for the optimal quantity choice, in two respects. First, the supplier internalizes the marginal indirect cost at the same rate as the marginal revenue only if $\left(1-\alpha r_{\eta}\right)=(1-\alpha)$. This does not hold as $r_{\eta}<1$, since the accounting system needs to allocate. ${ }^{20}$ Therefore not all of the economic cost from increased production is allocated to the reimbursed product. Consequently, the rate at which the supplier internalizes the marginal indirect cost is higher than the rate at which he internalizes the marginal revenue. This implies under-production incentives $\left(\hat{q}<q^{*}\right)$. With increasing returns to scale, low overall production level amplifies this under-production incentive.

Secondly, the marginal indirect cost, internalized by the supplier, is adjusted as the allocation rate $r_{\eta}$ itself correlates positively with the quantity of reimbursed products produced. ${ }^{21}$ In other words, with increased production more of the total cost of common input factors is allocated to the reimbursed products. This adjustment can be significant and lead to overproduction incentives if at least one of following conditions holds: (a) total cost of common input factors is high and (b) small changes in quantity have a relatively large impact on the allocation rate. In these cases, small changes in produced quantity allocate a large amount of total cost of common input factors to the reimbursed product. This benefit is scaled by $\alpha$, as the buyer must internalize the cost allocation for this to effect the supplier's incentives.

In conclusion, the supplier has incentives to engage in RAM, but it is ambiguous whether over- or underproduction takes place. With increasing returns to scale technology, it is not possible to solve for $q^{*}, \hat{q}_{D L}$ and $\hat{q}_{A B C}$ analytically because $q$ cannot be extracted from $\bar{A}^{\frac{1}{2 \beta}} \cdot{ }^{22}$ Therefore, relationships between $q^{*}, \hat{q}_{D L}$ and $\hat{q}_{A B C}$ are explored in section 6 using a numerical example.

\footnotetext{
${ }^{20} r_{\eta}=1$ implies a single-product firm and is ruled out by assumption. In a singleproduct firm cost allocation plays no role.

${ }^{21} \frac{\partial r_{\eta}}{\partial q}>0$. As $\Omega$ and $\mathbf{P}$ are exogenous, $Q$ is fixed and $m=0, q$ is the only variable in $r_{\eta}$.

${ }^{22} \bar{A}^{\frac{1}{2 \beta}}$ can be solved only if $\frac{1}{2 \beta}$ is an integer, which is true only if $\beta=0.5$.
} 


\subsubsection{Real Cost Management}

$\eta=D L$

Each per unit RCM has price $P_{1}$, the cost of labour. Therefore, the supplier's incentives to engage in RCM depends on two relative relationships. First, the relative relationship between total direct and indirect costs, conditional on the efficient input-factor choices. Second, the relationship between (a) the rate at which the supplier internalizes the cost of RCM and (b) the rate at which the buyer internalizes this cost. This follows from comparing the benefits and cost the supplier internalizes by engaging in RCM.

$$
\alpha c_{o h}^{*}\left(\frac{P_{1}\left(L_{1}+m\right) q}{c_{d l}^{*} P_{1}\left(L_{1}+m\right) q}-\frac{P_{1} L_{1} q}{c_{d l}^{*}}\right)>(1-\alpha) P_{1} m q
$$

The supplier has incentives to engage in RCM when total indirect production costs are high. The reason is that then even a small per unit manipulation has the potential to allocate a large fraction of the indirect costs to the reimbursed product. In addition, a small per unit RCM has the highest impact on the allocation rate, when total direct labour costs are low. These conditions are identical to the conditions that incentivized the supplier to engage in over-production in the previous section.

The following proposition presents a formal condition of the supplier's RCM incentives and the size of RCM.

Proposition 2. With any feasible trade quantity, ${ }^{23}$ a supplier with a directlabour based accounting system engages in RCM if:

$$
\alpha>\bar{\alpha}_{D L} \equiv \frac{c_{d l}^{*}}{c_{d l}^{*}+c_{o h}^{*}}
$$

When condition (15) holds, then

$$
m(q)_{D L}=\frac{c_{d l}^{*}}{P_{1} q}\left(\sqrt{\frac{c_{o h}^{*}}{c_{d l}^{*}} \frac{\alpha}{1-\alpha}}-1\right)
$$

The proof is in the appendix. ${ }^{24}$

Corollary 4.1. With the direct labour accounting system in place, there exist an IOR-contract that fails to prevent the supplier's incentive to engage in $R C M$, i.e. $\bar{\alpha}_{D L}<1$ regardless of $q, Q$ and $\Omega$.

\footnotetext{
${ }^{23} 0<q<\left(a-p_{t}\right) / b$. If the supplier is indifferent between engaging in RCM or not, it is assumed he will not.

${ }^{24}$ In Christensen and Demski (2003) $\alpha=1$, i.e. for any combination of efficient input factors, the supplier is incentivized to engage in RAM. Further, in limits as $\alpha \rightarrow 1, m \rightarrow \infty$ as would be the case in Christensen and Demski (2003) if input-factor were not limited to $\bar{x}_{i}$.
} 
This implies that small changes in the profit-sharing level can have significant efficiency effects, when $\alpha$ is around the threshold.

Relationship specific investments and cost reducing activities are often seen as IOR efficiency improving. However, Proposition 2 implies that these investment can have adverse effects as well. An investment that reduces the minimum direct labour requirements (i.e. reduction of $L_{1}$ ) increase the supplier's incentives to engage in RCM, but reduce the per unit RCM. An investments that reduces the minimum requirements of the intermediary output used in the products (i.e. reduction of $A_{1}$ ), decrease the supplier's incentives to engage in RCM, but increase the per unit RCM. The analysis of this paper cannot determine the net effect of either of these cost reducing investments.

$\eta=A B C$

The ABC accounting system induces efficient direct input choices. The cost of RCM arises from the excessive purchase of indirect input factors. Contrary to the DL system, the rate at which the supplier internalizes this cost is not transparent. The allocation rate and cost to be allocated are interdependent as $\frac{\partial c_{o h}}{\partial m}>0$. Further, the supplier internalizes the cost of $\mathrm{RCM}$ at a higher rate than in the DL system, as not all of the costs of the excessive factor inputs are allocated to the reimbursed product.

In addition to the supplier's stake in IOR, the incentives to engage in $\mathrm{RCM}$ and the magnitude of RCM depend on the use of intermediary output and production technology. The allocation rate is responsive to RCM if the reimbursed product uses relatively little of the intermediary output. The intuition is that then the denominator does not change much compared to the nominator. The responsiveness of the allocation rate is influenced by two elements: (a) the relationship between productivity variables $A_{1}$ and $A_{2}$ and (b) the buyer's importance as a customer (measured by units traded).

The cost of RCM is decreasing with economies of scale, and therefore the supplier's incentive to engage in RCM increases with $\beta$. Further, as the total production of the intermediary output increases, the cost of RCM decreases. As with the allocation rate responsiveness, the total production depends on the productivity variables, but only on the total production level (not the relationship between production quantities).

The productivity variables are by assumption non-observable. However, it is not unreasonable to assume that the buyer can collect information about the supplier's total business size.

Proposition 3. With any feasible trade quantity a supplier with an $A B C$ accounting system in place engages in RCM if:

$$
\alpha>\bar{\alpha}_{A B C} \equiv \frac{A_{1} q+A_{2} Q}{A_{1} q+2 \beta A_{2} Q}
$$


When condition 17 holds, then

$$
m(q)_{A B C}=\frac{(2 \beta \alpha-1)}{1-\alpha} \frac{A_{2} Q}{q}-A_{1}
$$

Corollary 4.2. If the supplier's production technology exhibits decreasing returns to scale, then he has no incentives to engage in the RCM. With constant returns to scale technology, even a small share of IOR profit disincintevizes the supplier form RCM. If the supplier's production process exhibits increasing returns to scale, then the supplier engage in RCM if his share of IOR profit is low.

An investment that reduces the need for the direct input, have no effect on the RCM when the supplier has implemented ABC accounting system. This is true regardless of the technology for producing the intermediary output. An investment that reduces the minimum requirement for the intermediary output of the traded (i.e. $A_{1}$ ) have the same effect regardless of the accounting system in place, when the technology exhibits increasing returns to scale. In other words, also with $\mathrm{ABC}$ accounting system, the conditions under which the supplier engage in RCM become more rigorous when $A_{1}$ decreases. But whenever the supplier engage in RCM, the per unit manipulation increase. ${ }^{25}$ An investment that reduces both $A_{1}$ and $A_{2}$ proportionally have no effect on the supplier's incentives to engage in RCM, but it will reduce the per unit RCM. $^{26}$

\section{Benchmarks}

Before illustrating the effect of RAM and RCM with numerical examples in the next section, two benchmarks, the first-best solution and the arm'slength trade solution, are introduced. In the first-best solution, the supplier's information advantage is irrelevant and efficient quantity and input-factor choices are made. In other words, in the first-best solution both RCM and RAM are zero. Also the total profit from the buyer-supplier relationship is at maximum.

Marginal costs are constant only under the following assumptions (i) substitution between direct and indirect input factors is not possible, and (ii) the production technology to produce the intermediary output exhibits constant returns to scale. With increasing returns to scale, the marginal cost of the traded product depends on the quantities produced (i.e. $q$ and $Q$ ), as the quantity of the intermediary product produced is affected. Under the set-up where supplier's information advantages matter and he can engage in

${ }^{26}$ Rewrite condition 17 to $\frac{2 \beta \alpha-}{1-\alpha}>\frac{A_{1} q}{A_{2} Q}$, then decreasing $A_{1}$ and $A_{2}$ by fraction $\gamma$ does not change the right hand side. However, $m^{\prime}(q)_{A B C}=(1-\gamma) \frac{(2 \beta \alpha-1)}{1-\alpha} \frac{A_{2} Q}{q}-A_{1}$.
} 
RCM and RAM, both $q$ and the amount of $y_{1}$ produced can be distorted, compared to the first-best. Therefore, the meaningful statistic is total profit.

The first-best profit, denoted $\Pi^{f b}$ is the maxim the buyer and the supplier can achieve altogether. Let $\pi_{\eta}^{S}$ denote the supplier's profit and $\pi_{\eta}^{B}$ the buyer's profit when the trade is governed by the IOR-contract and the supplier has implemented accounting system $\eta$. Then, the total IOR profit is

$$
\Pi_{\eta}^{I O R}=\pi_{\eta}^{S}+\pi_{\eta}^{B}
$$

and $\Pi^{f b} \geq \Pi_{\eta}^{I O R}, \eta=\{D L, A B C\}$.

The arm's-length relationship is the default governance mechanism. In the arm's-length relationship the supplier announces a wholesale price $w \forall q$. The wholesale price is decision relevant for the buyer and the final trading price. Then the buyer determines the trade quantity $\tilde{q}(w)$. Under arm'slength relationship, accounting plays no role. ${ }^{27}$

It is not obvious which of the trade governance mechanisms dominates, as IOR with opportunistic disclosure may induce quantity distortion (RAM) as well as RCM. Without further analysis it is unclear whether RAM manifests as over- or underproduction. Also when comparing the IOR-contract with the arm's-length trade, total profit is the meaningful statistic. Let, $\pi_{S}^{w}$ denote the supplier's profit under the arm's-length relationship and equivalently $\pi_{B}^{w}$ the buyer's profit. The total profit under the arm's-length relationship is then:

$$
\Pi^{w}=\pi_{w}^{S}+\pi_{w}^{B}
$$

In the following analysis and in the numerical examples, it is assumed that the supplier's technology exhibits constant or increasing returns to scale. First, an important reason for entering a buyer-supplier relationship is to access the supplier's superior production capabilities, including the economies of scale (Cooper and Slagmulder, 2004; Anderson and Dekker, 2009). Further, decreasing returns to scale does not induce RCM, when the supplier has implemented the ABC accounting system (Corollary 4.2; Christensen and Demski, 2003, Proposition 4). ${ }^{28}$

\footnotetext{
${ }^{27}$ Because the supplier knows his production technology, he also know marginal cost.

${ }^{28}$ Production technology employed in this paper is a simplified model of Christensen and Demski (2003). However, a more complex production of intermediary output, where one of the production processes exhibit decreasing return to scale may induce RCM when the supplier has implemented the ABC system (Christensen and Demski, 2003, Proposition $5)$.
} 


\subsection{I: First-best}

Let $q^{*}$ be the maximizer of $\Pi^{f b}$ (the first-best profit). Then the first-best program is:

$$
\max _{q} \Pi^{f b} \equiv\left(a_{0}-b_{0} q\right) q-\left(P_{1} L_{1} q+P_{2} L_{2} Q+\bar{A}^{\frac{1}{2 \beta}} \bar{P}\right)
$$

where $\bar{A}=\left[A_{1} q+A_{2} Q\right]$.

As $\frac{1}{2 \beta}$ is an integer only with constant returns to scale technology, it is not possible to find a general closed form solution for $q^{*}$. However, it is possible to give conditions under which a unique non-zero maximizer exists:

Lemma 5.1. With $\beta \geq 0.5$ a non-zero maximizer of (19) exist only if the following conditions are met:

1.

$$
\frac{\partial \Pi^{f b}}{\partial q}(0)>0 \Leftrightarrow a_{0}-2 b_{0} q>P_{1} L_{1}+\frac{A_{1}}{2 \beta} \bar{P}^{\left(\frac{1}{2 \beta}-1\right)}
$$

2.

$$
\frac{\partial^{2} \Pi^{f b}}{\partial q^{2}} \leq 0 \Leftrightarrow 2 b_{0} \geq \frac{\left(A_{1}\right)^{2}}{2 \beta}\left(1-\frac{1}{2 \beta}\right) \bar{P} \bar{A}^{\left(\frac{1}{2 \beta}-2\right)}
$$

The first condition ensures that the end-user market is attractive. The trade will take place, i.e. $q>0$ only if marginal revenue is above marginal production cost at least for one unit. The second condition is essential for the existence of an interior solution, i.e the slope of the inverse demand function must be steep enough compared to the increase in production costs.

\subsection{Benchmark II: Arm's-length relationship}

Conditional on the wholesale price $w$, the buyer's problem is:

$$
\begin{array}{r}
\max _{q} \pi_{w}^{B} \equiv\left(a_{0}-b q_{0}\right) q-w q \\
\Rightarrow \tilde{q}(w)=\frac{a_{0}-w}{2 b_{0}}
\end{array}
$$

Let $\pi_{S}$ denote the supplier's profit. Then the supplier's problem is:

$$
\begin{array}{r}
\max _{w} \pi_{w}^{S} \equiv w \tilde{q}(w)-C(\tilde{q}(w), Q ; \mathbf{P})= \\
w\left(\frac{a_{0}-w}{2 b_{0}}\right)-P_{1} L_{1}\left(\frac{a_{0}-w}{2 b_{0}}\right)-\bar{P}\left[A_{1}\left(\frac{a_{0}-w}{2 b_{0}}\right)+A_{2} Q\right]^{\frac{1}{2 \beta}}
\end{array}
$$


The solution is implicitly given by:

$$
w=\frac{1}{2}\left(a_{0}+P_{1} L_{1}+\frac{\bar{P} A_{1}}{2 \beta}\left[A_{1}\left(\frac{a_{0}-w}{2 b_{0}}\right)+A_{2} Q\right]^{\frac{1}{2 \beta}-1}\right)
$$

Equation (20) is equivalent to the first order conditions of the first-best program only if the wholesale price equals marginal cost. Equation (22) implies that this is not the case.

Some intuition can be obtained from the set-up with constant returns to scale (i.e. $\beta=0.5$ ), then:

$$
\begin{gathered}
\frac{\partial C(\cdot)}{\partial q}=P_{1} L_{1}+\bar{P} A_{1} \\
w^{C R S}=\frac{1}{2}\left(a_{0}+P_{1} L_{1}+\bar{P} A_{1}\right)
\end{gathered}
$$

Equations 23 and 24 imply that $w^{C R S}=\frac{\partial C(\cdot)}{\partial q}$ iff. $a_{0}=P_{1} L_{1}+\bar{P} A_{1}$. However, this implies that the market is not attractive and no trade takes place. $\tilde{q}(w)=0$ is confirmed by substituting $w=P_{1} L_{1}+\bar{P} A_{1}=a_{0}$ into the buyer's response function.

If the market is sufficiently attractive for the trade to take place $a_{0}>$ $P_{1} L_{1}+\bar{P} A_{1}$ the wholesale price set by the supplier is above the marginal cost. The consequence is that the quantity traded is the only half of the first-best quantity.

$$
\tilde{q}(w)^{C R S}=\frac{1}{2 b_{0}}\left(\frac{1}{2}\left(a_{0}-P_{1} L_{1}-\bar{P} A_{1}\right)\right)<q^{C R S *}=\frac{1}{2 b_{0}}\left(a_{0}-P_{1} L_{1}-\bar{P} A_{1}\right)
$$

In summary, the arm's-length relationship is subject to the double-marginalization problem. Therefore the IOR contract with opportunistic disclosure has potential to improve the efficiency of the trade. However, whether this potential is realized depends on the supplier's incentives to engage in RCM and RAM.

The IOR profit is bounded above by the first-best solution. However, an analytical comparison between $\Pi^{w}$ and $\pi^{I O R}$ is not possible when the supplier's production technology exhibits increasing (or decreasing) returns to scale. The reason is that if $\beta \neq 0.5$ it is not possible to derive closed form solutions for $q^{*}, q_{\eta}^{I O R}$ and $\tilde{q}(w)$. Therefore, the next section presents some numerical examples. 


\section{Numerical Example}

In this section, the analytical findings of Section 4 and benchmarks are illustrated. The advantage of this illustration is that contrary to the analytical approach, RCM and RAM are determined simultaneously. I use optimization software, ${ }^{29}$ which solves for RCM and RAM simultaneously using heuristic approach.

Three cases are presented. The 'Base Case' is chosen such that the traditional (DL) and the ABC accounting systems induce the same RAM effect, except when interaction with RCM takes place. Therefore, when RCM is zero, then in the 'Base Case' the cost report $(\hat{C}(\cdot))$ and thus the total IOR profit is independent of the accounting system implemented. In the 'Base Case' the allocation rate is the same under both accounting systems as long as RCM is zero. For high values of $\alpha$, i.e. when the supplier engage in $\mathrm{RCM}$, total IOR profits are not equal. The reason is that the magnitude of RCM always depend on the accounting system in place. 'Case 1' and 'Case 2 ' illustrate that the accounting system in place affects the IOR profit and efficiency loss from RAM and RCM. In 'Case 1' the DL accounting system outperforms the ABC. In 'Case 2' this is reversed.

Only the intensity of direct labour (cost) is varied across all three cases. This allows for more transparent comparison between these three cases. ${ }^{30}$

All three numerical examples are solved for $\alpha \in\{0,0.1, \ldots, 0.8,0.9\}$ separately. The "discrete step approach" makes it difficult to observe differences in threshold for supplier's incentives to engage in RCM (i.e. whether $\bar{\alpha}_{D L} \neq \bar{\alpha}_{A B C}$ ). In reporting 'Case 1' and 'Case 2' results for $\alpha<0.3$ are omitted, because low $\alpha$ aligns the supplier's and IOR's interest well and the efficiency loss is minimal.

Following parameter values are common in all three cases:

- The inverse demand function is $p_{0}=60-1 * q$

- The exogenously given price vector of input factors is $\mathrm{P}=\left[\begin{array}{llll}2 & 2 & 1 & 3\end{array}\right]$

- The minimum technical requirements for the intermediary output are: $A_{1}=A_{2}=6$

- Of two reasons, the economies of scale parameter is $\beta=0.7$. First, Noreen et al. (1994) find that the concavity of cost function matches (on average) production function with $\beta=0.7$. Secondly, the qualitative results of the examples does not crucially depend on the choice of $\beta$. If $\beta$ is lower, same qualitative results can be obtained by increasing the production volume, i.e. larger values of $a_{0}$ and $Q$.

\footnotetext{
${ }^{29}$ Matlab R2013b, Optimization toolbox.

${ }^{30}$ Similar effect is achieved if the direct labour costs are held fixed and the minimum use of the intermediary output varies.
} 
- The supplier's sells $Q=30$ units at the exogenous market. Further, all examples implement $R(30)=\$ 1.000 .^{31}$ This has no real effect on the supplier's choices, but avoids reporting negative profits.

\section{Base Case}

If $m=0, L_{1}=A_{1}, L_{2}=A_{2}$ and $P_{1}=P_{2}$ then $\hat{q}_{D L}=\hat{q}_{A B C}$ regardless of $\alpha$ and $\beta .{ }^{32}$ Set $L_{1}=L_{2}=A_{1}=A_{2}=6$.

To illustrate the use of the supply schedule, assume $\alpha=0.7$. This ensures that RCM incentives are muted. ${ }^{33}$ Therefore, in the 'Base Case' the supply schedule is constructed and manipulated in the same way, regardless the accounting system.

- The supplier's best quantity choice is $\hat{q}=23.32$

- The cost reported by the accounting system is $\hat{C}(\cdot)=373.14$.

- The buyer's profit is $\pi^{B}=337.58$.

For illustration purposes it is sufficient to construct the supply schedule for quantities just above and below $\hat{q}$. Let superscript ' + ' denote variables that relate to the quantities just above the supplier's choice and equivalently let the superscript '-' denotes variables related to the quantity just below the supplier's choice. Then:

- $q^{+}=\hat{q}+1=24.32$,

- $\hat{C}(\cdot)^{+}=388.62$ and

- $\pi^{B+}=335.39$

- $q^{-}=\hat{q}-1=22.32$,

- $\hat{C}(\cdot)^{-}=357.62$ and

- $\pi^{B-}=338.40$

If the supplier constructs the supply schedule truthfully, then the buyer has incentive to choose $q^{-}$as the trade quantity. In other words, $\tilde{q}<\hat{q}$. However, if the supplier increases the cost report for $q^{-}$by just $\$ 1.5$, then the reported cost are $\$ 359.12$, the buyer's profit decreases to $\$ 337.35$. Thereafter, it is in the buyer's best interest to choose $\tilde{q}=\hat{q}=23.32 .{ }^{34}$

\footnotetext{
${ }^{31}$ Throughout the numerical examples, the choice of monetary unit is arbitrary, as it has no effect on the qualitative results, it only serves expositional reasons

${ }^{32}$ The proof is in the appendix.

${ }^{33}$ Positive RCM does not have a qualitative effect on the use and construction of the supply schedule, however it does complicate the calculation.

${ }^{34}$ In practice, the supply schedule look like the supplier is offering quantity discount. In the 'Base Case', $\hat{q}=23.32$ would be the break-point, i.e. the quantity discount schedule would be: $\left(\tilde{q}<23.32, p_{t}=\$ 16.1\right)$ and $\left(\tilde{q} \geq 23.32, p_{t}=\$ 16.00\right)$.
} 


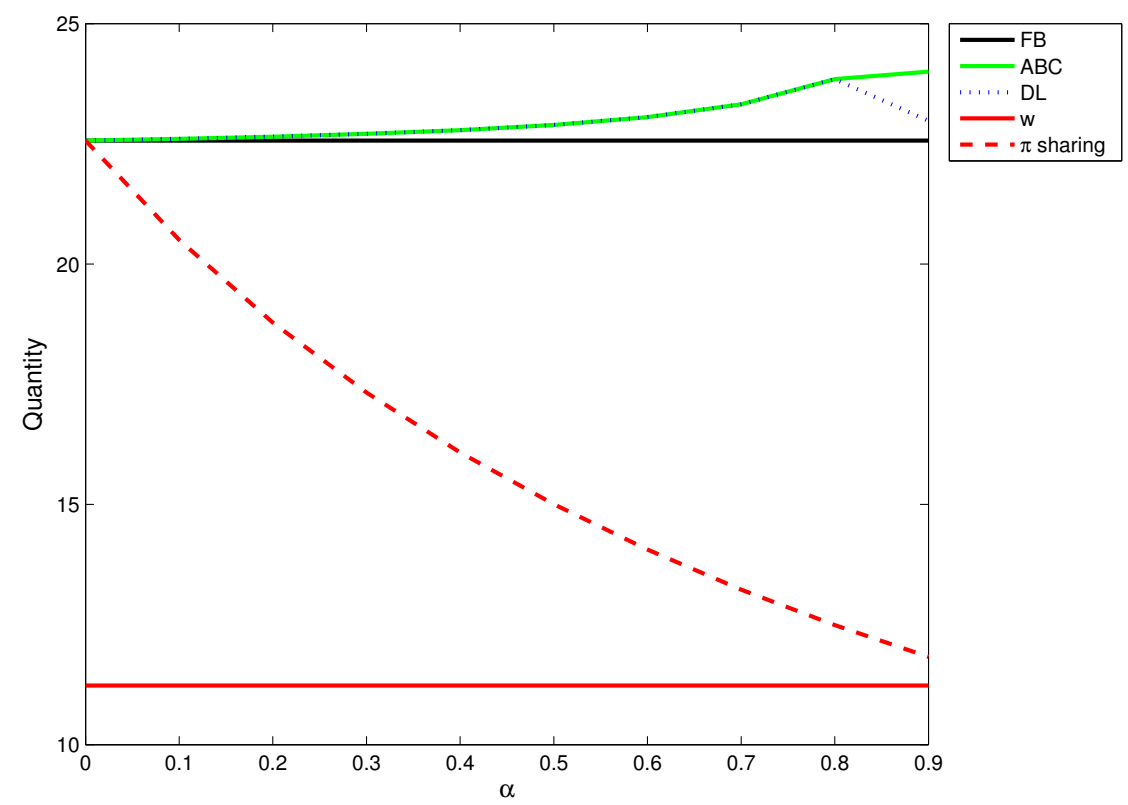

Figure 2: Base Case: Quantities, $q^{*}=22,56$ and $q^{w}=11,23$

For $\alpha \leq 0.8 \mathrm{RCM}$ is zero both in the $\mathrm{DL}$ and in the $\mathrm{ABC}$ accounting systems.

Figure 2 shows that IOR-contract induce overproduction compared to the first-best. If the trade is governed by profit-sharing arrangement without cost reimbursement, then underproduction will take place. The 'profitsharing only' contract mitigates the double-marginalization problem, especially when $\alpha$ is low. Distance between the red and the dashed red line shows the reduction in quantity distortion if 'profit-sharing only' contract is implemented.

Quantities with IOR-contract in Figure 2 exhibit a kink at $\alpha=0.8$ regardless of the accounting system implemented by the supplier (the green line represents $q_{A B C}$ and the dashed blue line $q_{D L}$ ). This is so as with low levels of supplier's incentive alignment, the supplier engage in RCM. In this example $m(\alpha=0.9)_{A B C}=\$ 13.5$ and $m(\alpha=0.9)_{D L}=\$ 4.2$. This affects both the quantities traded, but also the total IOR profit, as illustrated in Figure 3.

In summary, the IOR-contract can improve the efficiency of a buyersupplier relationship compared to an arm's-length arrangement and 'profitsharing only' contact. This holds even in the presence of the opportunistic disclosure, provided $\alpha$ is not too high. If the buyer's share of the profit is high, then the supplier finds it advantageous to engage in RCM. This 


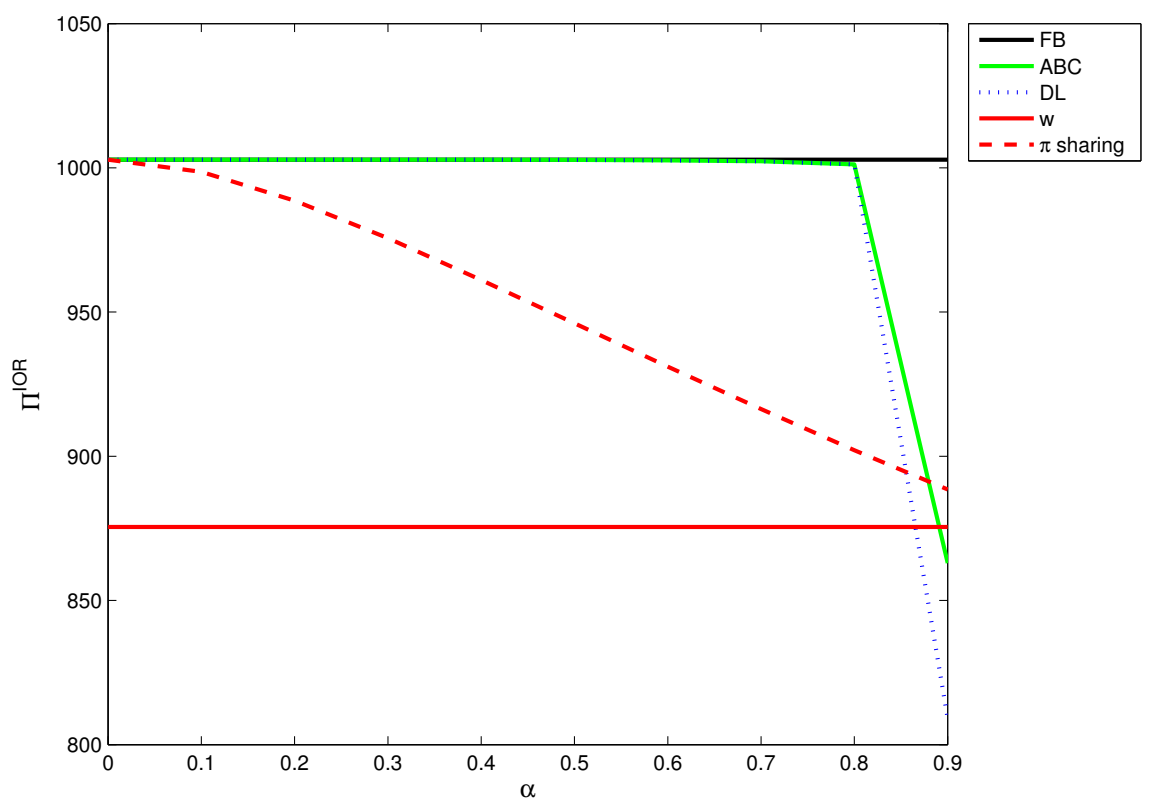

Figure 3: Base Case: IOR profit

has adverse effects for the IOR as whole. However, as argued above, small change in the incentive alignment can improve IOR efficiency. In this example an increasing the supplier's share from 0.1 to 0.2 increases IOR profit significantly.

'Case 1' and 'Case 2' illustrate, that the supplier's accounting system choice is not trivial in the context of IOR-contract.

\section{Case 1: The DL system dominates the ABC system:}

$$
\Pi_{D L}>\Pi_{A B C} \text { for } \alpha<\bar{\alpha}_{\eta}
$$

The productivity variables of direct inputs are: $L_{1}=4$ and $L_{2}=8$.

When the traded product is not labour intense (compared to the average labour intensity of the other products the supplier produces) and the supplier has implemented the traditional accounting system, he is incentivized to under produce compared to the first-best solution. The reason is that, an additional unit of the traded product does not impact the allocation rate sufficiently. Consequently the right hand side of the condition in Proposition 1 (i) is small. At the same time, the increase in indirect cost is internalized at relatively high rate. With $\alpha=0.7$ 


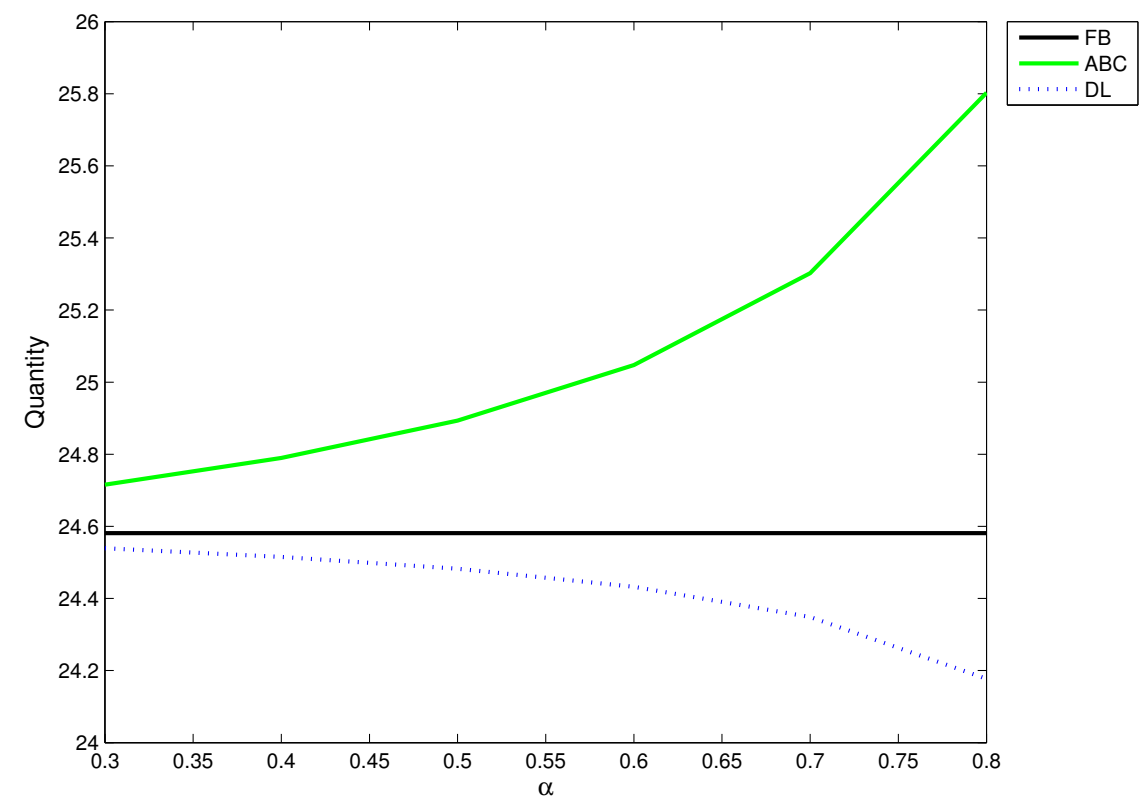

Figure 4: DL dominates ABC: Quantities

$$
\begin{aligned}
\left(1-\alpha r_{D L}\right) \frac{\partial c_{o h}^{*}}{\partial q} & \neq \frac{\partial r_{D L}}{\partial q} c_{o h}^{*} \\
2.267 & >1.823
\end{aligned}
$$

In 'Case 1', when ABC accounting system is implemented the supplier is incentivieszd to overproduce. ${ }^{35}$

When the other products the supplier's produces are, on average, more labour intense then the product traded within the IOR, then the total profit with direct labour based accounting system is above the the IOR profit with ABC.

\section{Case 2: The ABC system dominates the DL system:}

$$
\Pi_{A B C}>\Pi_{D L} \text { for } \alpha<\bar{\alpha}_{\eta}
$$

The productivity variables of direct inputs are: $L_{1}=8$ and $L_{2}=4$. Regardless of the accounting system, the supplier's best quantity choice is above the first-best. However, as producing one more unit affects the allocation rate more with the direct labour based accounting system than with the $\mathrm{ABC}$, the overproduction is more severe under the former. Consequently,

$$
{ }^{35}\left(1-\alpha r_{A B C}\right) \frac{\partial c_{o h}^{*}}{\partial q} \neq \frac{\partial r_{A B C}}{\partial q} c_{o h}^{*} \Leftrightarrow 1.922<2.147(\mathrm{P} 1 . \mathrm{i} \mathrm{C} 1 \mathrm{ABC})
$$




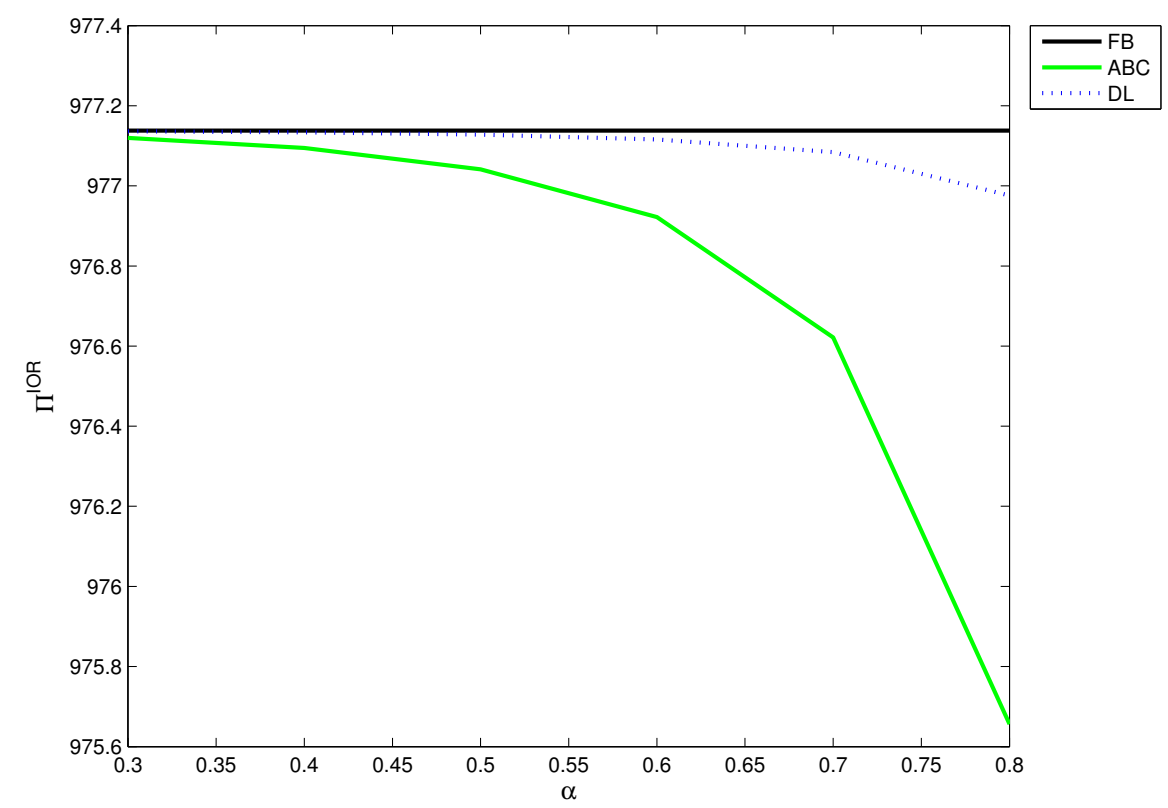

Figure 5: DL dominates ABC: IOR profit

the total IOR profit is higher when the supplier has implemented the ABC system. 


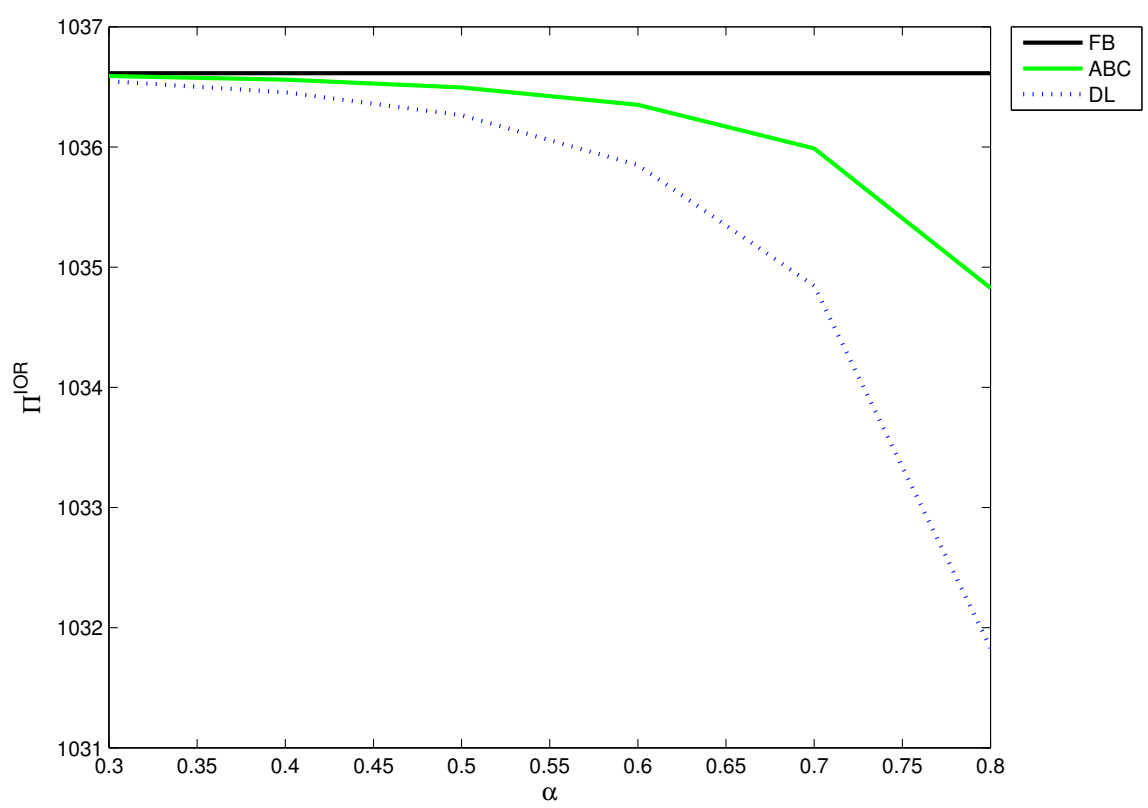

Figure 6: ABC dominates DL: IOR profit

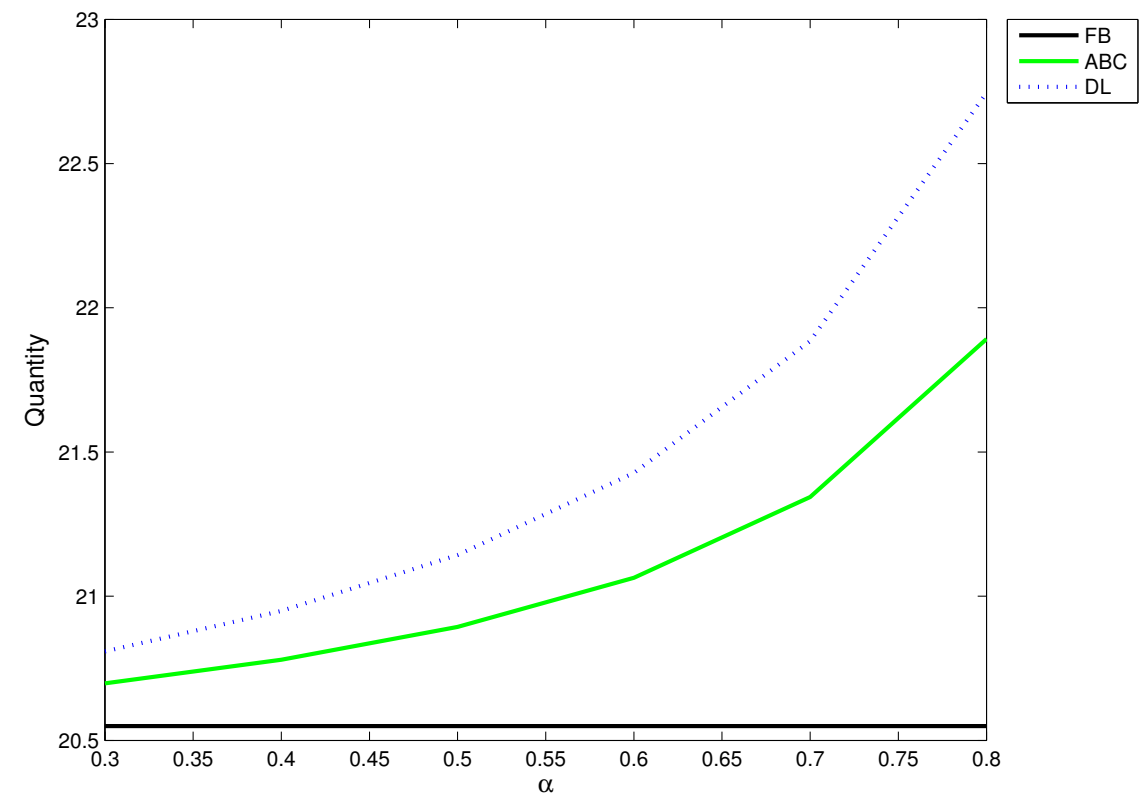

Figure 7: ABC dominates DL: Quantities 


\section{Discussion}

This paper demonstrates that an IOR-contract that implements cost reimbursement with profit-sharing can improve efficiency compared to the arm'slength trade. This is true even though the use of accounting cost information also induces supplier's opportunism. The underlying reason for opportunism is that the supplier knows the production technology, but the buyer does not. This incentivizes the supplier to manage the allocation rate used to allocate indirect production cost to the product traded within the IOR. Two mechanisms of opportunism are discussed. Real Cost Management is the supplier's inefficient input-factor choice in order to manage the allocation rate. RCM imposes real costs and therefore are used by the supplier only if he internalizes little of this cost. Choosing an appropriate level of supplier's stake in the profit generated by the trade is an efficient method for reducing RCM incentives.

Second, it is in the supplier's interest to affect the buyer's quantity choice. Both over- and underproduction may be in the supplier's best interest. Combining this fact with the buyer's information disadvantage ensures that the buyer cannot anticipate the distortion induced trough the supply schedule. The magnitude and direction of quantity distortion with IOR-contract are affected by the supplier's accounting system. Though the IOR-contract does not eliminate the quantity distortion, it is mitigated compared to the arm'slength and 'profit-sharing only' arrangements.

An implication is, that it is not enough that he buyer only learns about the productivity parameter related to the product traded within IOR. The buyer is able to back out the supplier's incentives only if she has a reasonably precise knowledge about the average product produced by the supplier. This may be an additional explanation to the practice of buyer's product and process engineers visiting the supplier's production sites. In the extant empirical literature, the explanation is, that the buyer acts altruistically and tries to help the supplier to reduce cost of the traded product and production processes (e.g., Cooper and Slagmulder, 1999).

A major cavity of the model is that it is deterministic. The opportunism is solely driven by the supplier's information advantage. It is unclear whether uncertainty increases or reduces the supplier's incentive to engage in opportunistic disclosure of accounting information. Future research could incorporate uncertainty about demand and/or the buyer's information advanatge in this respect; uncertainty about the exogenous market, the supplier also participates; or uncertainty about the production technology and input-factor prices. 


\section{References}

Aghion, P., M. Dewatripont, and P. Rey (1994). Renegotiation design with unverifiable information. Econometrica: Journal of the Econometric Society 62 (2), 257-282.

Aghion, P. and J. Tirole (1997). Formal and real authority in organizations. Journal of political economy, 1-29.

Agndal, H. and U. Nilsson (2008). Supply chain decision-making supported by an open books policy. International Journal of Production Economics 116(1), 154-167.

Agndal, H. and U. Nilsson (2009). Interorganizational cost management in the exchange process. Management Accounting Research 20(2), 85-101.

Agndal, H. and U. Nilsson (2010). Different open book accounting practices for different purchasing strategies. Management Accounting Research 21(3), 147-166.

Anderson, S. W. and H. C. Dekker (2009). Strategic cost management in supply chains, part 1: Structural cost management. Accounting Horizons 23(2), 201-220.

Baiman, S., P. E. Fischer, and M. V. Rajan (2000). Information, contracting, and quality costs. Management Science 46(6), 776-789.

Baiman, S. and M. V. Rajan (2002a). Incentive issues in inter-firm relationships. Accounting, Organizations and Society 27(3), 213-238.

Baiman, S. and M. V. Rajan (2002b). The role of information and opportunism in the choice of buyer-supplier relationships. Journal of Accounting Research 40(2), 247-278.

Bastl, M., T. Grubic, S. Templar, A. Harrison, and I.-S. Fan (2010). Interorganisational costing approaches: the inhibiting factors. International Journal of Logistics Management, The 21(1), 65-88.

Bhattacharyya, S. and F. Lafontaine (1995). Double-sided moral hazard and the nature of share contracts. The RAND Journal of Economics 26(4), $761-781$.

Cachon, G. P. (2003). Supply chain coordination with contracts. Handbooks in operations research and management science 11, 227-339.

Carr, C. and J. Ng (1995). Total cost control: Nissan and its uk supplier partnerships. Management Accounting Research 6(4), 347-365. 
Che, Y.-K. and D. B. Hausch (1999). Cooperative investments and the value of contracting. American Economic Review 89, 125-147.

Christensen, J. and J. S. Demski (2003). Factor choice distortion under costbased reimbursement. Journal of Management Accounting Research 15(1), $145-160$.

Cooper, R. and R. Slagmulder (1999). Supply chain development for the lean enterprise. interorganizational cost management.

Cooper, R. and R. Slagmulder (2004). Interorganizational cost management and relational context. Accounting, Organizations and Society 29(1), 1-26.

Dekker, H. C. (2003). Value chain analysis in interfirm relationships: a field study. Management Accounting Research 14(1), 1-23.

Dekker, H. C. (2008). Partner selection and governance design in interfirm relationships. Accounting, Organizations and Society 33(7), 915-941.

Demski, J. S. and D. E. Sappington (1991). Resolving double moral hazard problems with buyout agreements. The RAND Journal of Economics 22(2), 232-240.

Drake, A. R. and S. F. Haka (2008). Does abc information exacerbate hold-up problems in buyer-supplier negotiations? The Accounting Review 83(1), $29-60$.

Dye, R. A. (1985). Disclosure of nonproprietary information. Journal of accounting research 23(1), 123-145.

Edlin, A. S. and B. E. Hermalin (2000). Contract renegotiation and options in agency problems. Journal of Law, Economics, and Organization 16(2), 395-423.

Grossman, S. J. and O. D. Hart (1986). The costs and benefits of ownership: A theory of vertical and lateral integration. The Journal of Political Economy 94(3), 691-719.

Kajüter, P. and H. I. Kulmala (2005). Open-book accounting in networks: Potential achievements and reasons for failures. Management Accounting Research 16(2), 179-204.

MacLeod, W. B. and J. M. Malcomson (1993). Investments, holdup, and the form of market contracts. The American Economic Review 83(4), 811-837.

Munday, M. (1992). Accounting cost data disclosure and buyer-supplier partnerships - a research note. Management Accounting Research 3(3), 245-250. 
Nöldeke, G. and K. M. Schmidt (1995). Option contracts and renegotiation: a solution to the hold-up problem. The RAND Journal of Economics 26(2), 163-179.

Noreen, E., E. Noreen, and N. Soderstrom (1994). Are overhead costs strictly proportional to activity?: Evidence from hospital departments. Journal of Accounting and Economics 17(1), 255-278.

Rogerson, W. P. (1992). Overhead allocation and incentives for cost minimization in defense procurement. The Accounting Review 67(4), 671-690.

Seal, W., J. Cullen, A. Dunlop, T. Berry, and M. Ahmed (1999). Enacting a european supply chain: a case study on the role of management accounting. Management Accounting Research 10(3), 303-322.

Smirnov, V. and A. Wait (2004). Hold-up and sequential specific investments. RAND Journal of Economics 35(2), 386-400.

Verrecchia, R. E. (1983). Discretionary disclosure. Journal of accounting and economics 5, 179-194.

\section{A Appendix}

\section{Program to derive the supplier's cost function:}

$$
\min _{\mathbf{x}} C(q ; P) \equiv \sum_{i=1}^{4} x_{i} P_{i}
$$

Subject to:

$$
\begin{array}{r}
x_{1} \geq L_{1} q \\
x_{2} \geq L_{2} q Q \\
\left(x_{3} x_{4}\right)^{\beta} \geq \bar{A}
\end{array}
$$

where $\bar{A} \equiv A_{1} q+A_{2} Q$.

Let $\lambda_{j}$ denote the multiplier associated with the constraint $j$ (i.e. $j=$ $1,2,3)$, then the first order conditions of the Lagrange are: 


$$
\begin{aligned}
& \frac{\partial \mathscr{L}}{\partial x_{1}}=P_{1}+\lambda_{1} \\
& \frac{\partial \mathscr{L}}{\partial x_{2}}=P_{2}+\lambda_{2} \\
& \frac{\partial \mathscr{L}}{\partial x_{3}}=P_{3}+\lambda_{3} \beta x_{3}^{\beta-1} x_{4}^{\beta} \\
& \frac{\partial \mathscr{L}}{\partial x_{4}}=P_{4}+\lambda_{3} \beta x_{3}^{\beta} x_{4}^{\beta-1} \\
& \frac{\partial \mathscr{L}}{\partial \lambda_{1}}=x_{1}-L_{1} q \\
& \frac{\partial \mathscr{L}}{\partial \lambda_{2}}=x_{2}-L_{2} Q \\
& \frac{\partial \mathscr{L}}{\partial \lambda_{3}}=\left(x_{3} x_{4}\right)^{\beta}-\bar{A}
\end{aligned}
$$

As all input prices, $\beta$ and both $x_{3}$ and $x_{4}$ are positive, ${ }^{36}$ First order conditions in equations (28) to (31) imply that all constraints are binding. In other words, in efficient state, the firm has no reason to acquire more inputs than necessary. Further, the direct inputs are $x_{1}=L_{1} q$ and $x_{2}=L_{2} Q$ (equations 32 and 33). The acquired quantity of the indirect inputs $x_{3}$ and $x_{4}$ are less obvious.

Using equation (30):

$$
\lambda_{3}=-\frac{P_{3}}{\beta x_{3}^{\beta-1} x_{4}^{\beta}}
$$

Substituting $\lambda_{3}$ into (31):

$$
x_{4}=\frac{P_{3}}{P_{4}} x_{3}
$$

Then substituting $x_{4}$ into (34):

$$
x_{3}=\bar{A}^{\frac{1}{2 \beta}} \sqrt{\frac{P_{4}}{P_{3}}}
$$

And thus by (36): $x_{4}=\bar{A}^{\frac{1}{2 \beta}} \sqrt{\frac{P_{3}}{P_{4}}}$

Then the supplier's cost function is:

$$
C(q ; P)=P_{1} L_{1} q+P_{2} L_{2} Q+\overline{P A}^{\frac{1}{2 \beta}}
$$

where $\bar{P} \equiv 2 \sqrt{P_{3} P_{4}}$.

\footnotetext{
${ }^{36}$ Cobb-Douglas specification demands that both input variables are positive.
} 


\section{Proof of Proposition 1}

Let $m=\bar{m}$ be a fixed per unit RCM. First order conditions to equations 19, 10 and 12 are respectively:

$$
\begin{aligned}
& a_{0}-2 b_{0} q=P_{1} L_{1}+\frac{\partial c_{o h}^{*}}{\partial q} \\
&(1-\alpha)\left(a_{0}-2 b_{0} q\right)= \\
&(1-\alpha)\left(P_{1} L_{1}+P_{1} \bar{m}+\frac{1-\alpha r_{D L}}{1-\alpha} \frac{\partial c_{o h}^{*}}{\partial q}-\frac{\alpha}{1-\alpha} \frac{\partial r_{D L}}{\partial q} c_{o h}^{*}\right) \\
&(1-\alpha)\left(a_{0}-2 b_{0} q\right)= \\
&(1-\alpha)\left(P_{1} L_{1}+\frac{1-\alpha r_{A B C}}{1-\alpha} \frac{\partial c_{o h}}{\partial q}-\frac{\alpha}{1-\alpha} \frac{\partial r_{A B C}}{\partial q} c_{o h}\right)
\end{aligned}
$$

Where $c_{o h}^{*}=\bar{P} \bar{A}^{\frac{1}{2 \beta}}$ and $\frac{\partial c_{o h}^{*}}{\partial q}=\bar{P} A_{1} \frac{1}{2 \beta} \bar{A}^{\frac{1-2 \beta}{2 \beta}}$,

$$
\begin{aligned}
& c_{o h}=\bar{P}\left[\left(A_{1}+\bar{m}\right) q+A_{2} Q\right]^{\frac{1}{2 \beta}} \text { and } \\
& \frac{\partial c_{o h}}{\partial q}=\bar{P}\left(A_{1}+\bar{m}\right) \frac{1}{2 \beta}\left[\left(A_{1}+\bar{m}\right) q+A_{2} Q\right]^{\frac{1-2 \beta}{2 \beta}}
\end{aligned}
$$

With $\bar{m}=0, c_{o h}=c_{o h}^{*}$, thus a general condition can be derived. If $q^{*}=\hat{q}_{\eta}$, then the marginal costs are same, i.e.:

$$
\begin{array}{r}
\frac{\partial c_{o h}^{*}}{\partial q}=\frac{1-\alpha r_{\eta}}{1-\alpha} \frac{\partial c_{o h}^{*}}{\partial q}-\frac{\alpha}{1-\alpha} \frac{\partial r_{\eta}}{\partial q} c_{o h}^{*} \\
\Leftrightarrow\left(1-r_{\eta}\right) \frac{\partial c_{o h}^{*}}{\partial q}=\frac{\partial r_{\eta}}{\partial q} c_{o h}^{*}
\end{array}
$$

Then from $\hat{q}_{D L}=\hat{q}_{A B C}$ it follows that both the marginal and total overhead costs are same across accounting systems.

$$
\begin{array}{r}
\frac{\left(1-\alpha r_{D L}\right)}{1-\alpha} \frac{\partial c_{o h}^{*}}{\partial q}-\frac{\alpha}{1-\alpha} \frac{\partial r_{D L}}{\partial q} c_{o h}^{*}=\frac{\left(1-\alpha r_{A B C}\right)}{1-\alpha} \frac{\partial c_{o h}^{*}}{\partial q}-\frac{\alpha}{1-\alpha} \frac{\partial r_{A B C}}{\partial q} c_{o h}^{*} \\
\Leftrightarrow\left(r_{A B C}-r_{D L}\right) \frac{\partial c_{o h}^{*}}{\partial q}=\left(\frac{\partial r_{D L}}{\partial q}-\frac{\partial r_{A B C}}{\partial q}\right) c_{o h}^{*}
\end{array}
$$

\section{Proof of Proposition 2}

Rewrite suppliers profit function:

$$
\begin{array}{r}
\pi_{D L}^{S}=(1-\alpha)\left(a_{0}-b_{0} q\right) q-c_{d l}^{*}-c_{o h}^{*}-P_{1} q m+ \\
\alpha P_{1} q\left(L_{1}+m\right)\left(1+\frac{c_{o h}^{*}}{c_{d l}^{*}+P_{1} q_{1} m}\right)
\end{array}
$$

then 


$$
\begin{array}{r}
\frac{\partial \pi_{D L}^{S}}{\partial m}=-(1-\alpha) P_{1} q+\alpha P_{1} q \frac{c_{o h}^{*}}{c_{d l}^{*}+P_{1} q m}\left(1-\frac{P_{1} q m}{c_{d l}^{*}+P_{1} q m}\right)=0 \\
\Leftrightarrow \\
\frac{1-\alpha}{\alpha}=\frac{c_{o h}^{*} c_{d l}^{*}}{\left(c_{d l}^{*}+P_{1} q m\right)^{2}} \\
\Leftrightarrow \\
\left(c_{d l}^{*}\right)^{2}+2 c_{d l}^{*} P_{1} q m+\left(P_{1} q m\right)^{2}=c_{o h}^{*} c_{d l}^{*} \frac{\alpha}{1-\alpha}
\end{array}
$$

Some rearranging gives following quadratic polynomial equation for $m$ :

$$
\frac{P_{1} q}{c_{d l}^{*}} m^{2}+2 m+\frac{c_{d l}^{*}-c_{o h}^{*} \frac{\alpha}{1-\alpha}}{P_{1} q}=0
$$

As negative manipulation is not possible, we are interested only in positive real roots. As $\frac{P_{1} q}{c_{d l}^{*}}>0 \forall q>0$ by assumption, then the condition for positive manipulation reduces to (in terms of standard polynomial equation):

$$
-b+\sqrt{b^{2}-4 a c}>0
$$

Which reduces to: $a c<0$ and thus gives:

$$
\begin{array}{r}
\frac{P_{1} q}{c_{d l}^{*}} \frac{c_{d l}^{*}-c_{o h}^{*} \frac{\alpha}{1-\alpha}}{P_{1} q}<0 \\
\Leftrightarrow \\
\frac{c_{o h}^{*}}{c_{d l}^{*}}>\frac{1-\alpha}{\alpha}
\end{array}
$$

Substituting $b=2$ in the standard equation, it is easy to show that the condition (39) is more restrictive than needed to ensure real roots, i.e.

$$
a c \leq 1 \Leftrightarrow \frac{c_{o h}^{*}}{c_{d l}^{*}} \geq 0
$$

Further, substituting $\mathrm{b}=2$ in the standard equation, it reduces to: $1 / a(\sqrt{1-a c}-$ $1)$, which gives $m_{D L}=\frac{c_{d l}^{*}}{P_{1} q}\left(\sqrt{\frac{c_{o h}^{*}}{c_{d l}^{*}} \frac{\alpha}{1-\alpha}}-1\right)$.

Finally, the condition in Proposition 2.(i) is obtained by solving Equation (39) for $\alpha$.

\section{Proof of Proposition 3}

$$
\frac{\partial \pi_{A B C}^{S}}{\partial m}=\bar{P}\left(-\frac{\partial{\overline{A_{m}}}^{\frac{1}{2 \beta}}}{\partial m}+\alpha\left(\frac{\partial r_{A B C}}{\partial m}{\overline{A_{m}}}^{\frac{1}{2 \beta}}+r_{A B C} \frac{\partial{\overline{A_{m}}}^{\frac{1}{2 \beta}}}{\partial m}\right)\right)
$$


Where $\frac{\partial{\overline{A_{m}}}^{\frac{1}{2 \beta}}}{\partial m}=\frac{1}{2 \beta}{\overline{A_{m}}}^{\frac{1}{2 \beta}-1} q, r_{A B C}=\frac{\left(A_{1}+m\right) q}{\overline{A_{m}}}$ and $\frac{\partial r_{A B C}}{\partial m}=\frac{q \overline{A_{m}}-q^{2}\left(A_{1}+m\right)}{{\overline{A_{m}}}^{2}}$.

$$
\begin{aligned}
\left(\bar{P}{\overline{A_{m}}}^{\frac{1}{2 \beta}}-1\right) \frac{1}{2 \beta} & =\left(\bar{P}{\overline{A_{m}}}^{\frac{1}{2 \beta}-1} q\right) \alpha\left(\frac{\overline{A_{m}}-q\left(A_{1}+m\right)}{\overline{A_{m}}}+\frac{1}{2 \beta} \frac{\left(A_{1}+m\right)}{\overline{A_{m}}}\right) \\
& \Leftrightarrow \overline{A_{m}}=\alpha\left(2 \beta A_{2} Q+\left(A_{1}+m\right) q\right) \\
& \Leftrightarrow(1-\alpha)\left(A_{1}+m\right) q=(\alpha 2 \beta-1) A_{2} Q
\end{aligned}
$$

$$
m=\frac{(\alpha 2 \beta-1)}{(1-\alpha)} \frac{A_{2} Q}{q}-A_{1}
$$

Finally, the condition in Proposition 3.(i) solves for $m_{A B C} \geq 0$ and subsequently for $\alpha$.

\section{Proof of the Base Case selection criteria:}

If $L_{1}=A_{1}, L_{2}=A_{2}$ and $P_{1}=P_{2}$ then $\hat{q}_{D L}=\hat{q}_{A B C}$ regardless of $\alpha$ and $\beta$.

In both condition below (adapted from Proposition 1), the first equality holds if $P_{1}=P_{2}$ and the second holds if $L_{1}=A_{1}$ and $L_{2}=A_{2}$.

$$
\begin{array}{r}
\frac{P_{1} L_{1} q}{P_{1} L_{1} q+P_{2} L_{2} Q}=\frac{L_{1} q}{L_{1} q+L_{2} Q}=\frac{A_{1} q}{A_{1} q+A_{2} Q} \\
\Rightarrow\left(r_{A B C}-r_{D L}\right)=0 \\
\frac{P_{1} L_{1} P_{2} L_{2} Q}{\left[P_{1} L_{1} q+P_{2} L_{2} Q\right]^{2}}=\frac{P^{2}\left(L_{1} L_{2} Q\right)}{P^{2}\left[L_{1} q+L_{2} Q\right]^{2}}=\frac{A_{1} A_{2} Q}{\left[A_{1} q+A_{2} Q\right]^{2}} \\
\Rightarrow \frac{\partial r_{D L}}{\partial q}-\frac{\partial r_{A B C}}{\partial q}=0
\end{array}
$$

